\title{
Analisa Persepsi Verifikator Terhadap Kode Tindakan Medis Di RS Umum Citra Bunda Medical Center Padang
}

\author{
Dewi Mardiawati ${ }^{1}$, Linda Handayuni ${ }^{2}$ \\ ${ }^{1,2}$ STIKes Dharma Landbouw Padang
}

\section{Article Info}

Article history:

Received Jan 12, 2021

Revised August 18, 2021

Accepted August 24, 2021

\section{Keywords:}

Form A

Form B

Medical record file

Completeness

\begin{abstract}
ABSTRAK
Based on the initial survey conducted by researchers, it was found that there were differences in perceptions between code verifiers and BPJS verifiers regarding medical action codes. In February, there were 15 disease codes with different perceptions, because hospitals had to follow the code based on BPJS. The purpose of the study was to analyze the perception of the medical code of action by the verifier at Bunda Medical Center Hospital. This type of research is qualitative with a phenomenological approach. The study was conducted by indepth interviews with 1 medical support person, 1 medical committee, 1 code verifier, and 1 BPJS verifier, using a voice recorder and using interview guidelines. Data were analyzed using the Collaizzi method. The results showed that what hindered the implementation of the verification of the medical action code was that the doctor's writing was difficult to read by the verifier. There are differences in the verifier's perception of the medical code of action, where the verification of the medical action code is based on the number of resources used in the service, while the BPJS verifier considers the medical action code to be based on the severity or level of severity. The conclusion in this study is that the educational qualifications between the BPJS verifier and the verification of the medical action code are not appropriate, then the BPJS verifier verification of the code based on the severity level must be based on the most resources issued, So between BPJS officials and hospitals must have the same perception so no more error.
\end{abstract}

\section{Corresponding Author:}

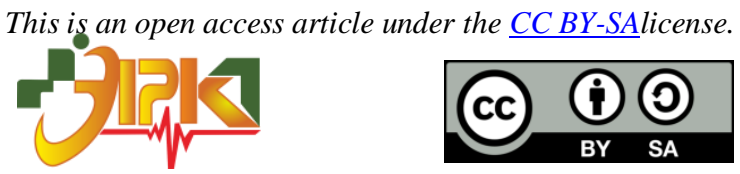

Dewi Mardiawati,

Program Studi D-3 Perekam dan Informasi Kesehatan,

STIKes Dharma Landbouw Padang,

Jl. Jhoni Anwar No. 29 Ulak Karang Utara, Kec. Padang Utara, Kota Padang Sumatera Barat.

Email: dmardiawati@gmail.com

\section{PENDAHULUAN}

Perbedaan persepsi verifikator tentang kode tindakan medis terlihat dari penelitian yang telah dilakukan. Menurut penelitian [1] dimana hasil penelitian menunjukkan yang menghambat kelancaran pelaksanaan pengodean tindakan medis adalah ketidakjelasan tulisan dokter sebagai penegak diagnosa dan tindakan medis serta ketidaklengkapan pengisian resume. Pengkodean disistem komputerisasi belum maksimal karena petugas koding masih baru. Sebaiknya rumah sakit melakukan penguatan input, dibidang SDM 
dengan meningkatkan keterampilan melalui pelatihan. Penelitian [2] penyebab pengembalian klaim pasien rawat inap terkait akurasi koding diantaranya karena kurangnya pemeriksaan penunjang pendukung diagnosis, ketidaktepatan pemberian kode oleh koder, dan ketidaksesuaian dengan rule MB dan consensus. Pengkodingan yang sangat berpengaruh dalam pelayanan jaminan kesehatan yang diberikan kepada warga Negara Indonesia.

Menurut [3] mengamanatkan dimana jaminan sosial bagi seluruh warga Indonesia termasuk JKN didalam suatu Badan Penyelenggara Jaminan Sosial, untuk JKN dilaksanakan BPJS Kesehatan dimulai pada tanggal 1 januari 2014 [4]. Jaminan Kesehatan Nasional (JKN) yang ada di Indonesia merupakan bagian dari Sistem Jaminan Jaminan Sosial Nasional (SJSN). UU No. 40 Tahun 2004 mendasari SJSN ini pelaksanaannya melalui asuransi kesehatan nasional yang wajib (mandatory). Tujuannya dari JKN adalah agar warga Indonesia dapat telindungi dan dapat memenuhi kebutuhan dasar kesehatan masyarakat [4].

Asuransi kesehatan bertujuan agar dapat mengurangi risiko masyarakat dalam menanggung biaya kesehatan dari keuangannya sendiri, biaya yang dibutuhkan tidak dapat diprediksi dan juga memerlukan biaya yang sangat besar. Untuk mengurangi biaya yang dibutuhkan untuk kesehatan maka dibentuk jaminan yaitu asuransi kesehatan, peserta yang ikut asuransi diwajibkan membayar premi dengan besaran biaya yang telah ditetapkan. Untuk pembiayaan kesehatan ditanggung secara bersama atau dikenal dengan bergotongroyong oleh keseluruhan peserta, sehingga biaya kesehatan yang dikeluarkan tidak memberatkan bagi orang-perorang [4].

Menurut [4] menjelaskan penyelenggara pelayanan kesehatan bekerjasama dengan BPJS kesehatan yaitu berupa fasilitas kesehatan tingkat pertama (puskesmas, praktik dokter, praktik dokter gigi, klinik pratama, rumah sakit kelas D) dan fasilitas kesehatan rujukan tingkat lanjutan (RTL) seperti (klinik utama, rumah sakit umum (RSU) dan khusus). Menurut [5] [6] menjelaskan, rumah sakit adalah tempat yang pelayanan kesehatan yang paripurna dimana menyediakan layanan rawat inap, rawat jalan, gawat darurat dan berbagai bidang penyakit.

Menurut [7] rekam medis adalah berkas, catatan atau dokumen yang berisikan identitas pasien, hasil pemeriksaan, pengobatan yang diberikan, serta tindakan dan layanan kesehatan yang diberikan kepada pasien. Dengan adanya rekam medis sehingga memudahkan petugas rekam medis dalam memberikan kode terhadap penyakit pasien. [8] menjelaskan, koding adalah suatu kegiatan untuk mengkode diagnosis utama dan sekunder mengunakan ICD-10, memberikan kode tindakan dengan ICD-9-CM. Koding penting dalam menentukan besarnya biaya yang dibayarkan kepada rumah sakit. Sumber data koding tersebut yaitu rekam medis pada formulir resume medis.

ICD-9-CM (Clinical Modification) adalah pengkodean tindakan/prosedur bedah/operasi dan non operasi seperti CT-Scan, MRI, dan USG. ICD-9-CM merupakan daftar yang tersusun dalam bentuk tabel dan index alfabetis. Tindakan bedah atau operasi dikelompokkan dibagian 01-86, sedangkan non operasi dibatasi dibagian 87-99 dan terdiri dari 16 bab [9]. Struktur klasifikasi dilihat dari anatomi dalam bentuk kode berupa numerik.

Pembiayaan kesehatan penting untuk implementasi Jaminan Kesehatan Nasional $(\mathrm{JKN})$. Metode pembayaran di program Jaminan Kesehatan Masyarakat (Jamkesmas). Dikenal dengan Casemix (case based payment) diterapkan sejak tahun 2008. Sejak berlakukannya sistem casemix di Indonesia dihasilkan 3 kali perubahan besaran tarif yang dikenakan kepada penyakit pasien [8].

Menurut [9] menjelaskan bahwa yang bertugas dan bertanggung jawab untuk mendapatkan hasil grouper yang benar diperlukan adanya kolaborasi yang baik antara 
dokter dan koder. [10] menjelaskan, perekam medis adalah seorang yang telah menamatkan pendidikan rekam medis dan informasi kesehatan memiliki ijazah dengan ketentuan dan peraturan perundang-undangan, petugas rekam medis dalam melaksanakan pekerjaannya di fasilitas pelayanan kesehatan mempunyai salah satu kewenangan yaitu melaksanakan pengklasifikasi klinis dan pengkodean diagnosa penyakit dan pengkodean tindakan medis.

RS Umum Citra Bunda Medical Center Padang memiliki tenaga rekam medis yang berjumlah 26 orang, dimana pada bagian ruang rekam medis terdapat 13 orang petugas, bagian ruang admission ada 5 orang petugas, dan pada bagian ruang casemix memiliki 8 orang petugas. Masing-masing ruang tersebut memiliki kepala ruangan dan ruangan tersebut dipimpin oleh kepala penunjang medis. Peneliti melakukan survey awal dengan cara wawancara yang dilakukan pada kepada verifikator kode yang sekaligus sebagai kepala ruangan dibagian casemix, didapatkan permasalahan adanya perbedaan persepsi antara verifikator kode dengan verifikator BPJS tentang kode tindakan medis, dengan adanya perbedaan persepsi tersebut maka berdampak kepada klaim yang dipending pembayarannya oleh BPJS kepada rumah sakit.

Pada bulan Februari 2019 ada 600 buah klaim yang diajukan kepada BPJS dimana dari 600 buah klaim tersebut terdapat 130 klaim yang terpending karena adanya masalah administrasi, masalah medis, dan karena perbedaan persepsi. Dari 130 tersebut klaim yang terpending karena perbedaan persepsi ada 15 buah kode tindakan medis yang persepsinya berbeda.

Peneliti melakukan wawancara kembali pada dengan verifikator kode sekaligus sebagai kepala ruangan casemix tersebut, didapatkan hasil bahwa karena perbedaan persepsi kode tersebut rumah sakit telah dianggap melakukan upcoding oleh BPJS. Jika masalah perbedaan persepsi tersebut tidak juga dapat kesepakatan kode yang sebenarnya maka klaim tersebut akan dinaikkan keatas yaitu bagian DPM (Dewan Pertimbangan Medik) dimana klaim tersebut akan lebih lama lagi terpendingnya, maka rumah sakit pun akhirnya mengikuti kode berdasarkan BPJS sehingga rumah sakit merasa dirugikan. Salah satu contohnya yaitu ada diagnosa abses dengan tindakan eksisi, verifikator kode mengkode tindakan medis nya yaitu eksisi dengan kode 86.3 sementara verifikator BPJS mengkode tindakan eksisi tersebut dengan kode 86.22. Peneliti juga melakukan wawancara kepada kepala ruangan casemix tentang pendidikan terakhir verifikator kode dan verifikator BPJS dan didapatkan hasil dari wawancara tersebut bahwa pendidikan terakhir verifikator kode yaitu D-3 rekam medis sedangkan pendidikan terakhir verifikator BPJS yaitu sarjana kesehatan masyarakat. Penelitian ini bertujuan menganalisis permasalahan pada komponen input dan proses pada perbedaan persepsi verifikator tentang kode tindakan medis di RS Umum Citra Bunda Medical Center Padang.

\section{METODE PENELITIAN}

Pelaksanaan penelitian dilaksanakan pada Maret-Agustus, sedangkan untuk pengumpulan data dilakukan pada tanggal 27 Juli sampai dengan 7 Agustus tahun 2020. Jenis penelitian adalah kualitatif dengan jenis pendekatan fenomenologi. Sampel dalam penelitian ini adalah 1 orang penunjang medis, 1 orang komite medik, 1 orang petugas verifikator kode di RS Umum Citra Bunda Medical Center Padang dan 1 orang verifikator BPJS sehingga berjumlah 4 orang informan.

Data dikumpulkan yaitu melalui wawancara mendalam (In Depth Interview) dengan menggunakan instrumennya yaitu tape recorder atau perekam suara untuk merekam semua wawancara tersebut dan pedoman wawancara. Analisis data pada penelitian menggunakan model Collaizzi untuk analisis data dan validasi data dengan metode triagulasi. 


\section{HASIL DAN PEMBAHASAN \\ Komponen Input}

a. Sumber Daya Manusia

1. Kualifikasi Pendidikan

Berdasarkan wawancara mendalam kepada informan 1, 3 dan 4 untuk kualifikasi pendidikan dalam memverifikasi kode tindakan medis di RS Umum Citra Bunda Medical Center Padang sudah sesuai. Informan 1 menyatakan bahwa kalau untuk verifikator kode di rumah sakit sudah sesuai kualifikasi pendidikannya karena tugas perekam medis yaitu mengkode akan tetapi kualifikasi pendidikan verifikator BPJS jika untuk memverifikasi kode tindakan medis belum sesuai karena verifikator BPJS tersebut memiliki latar belakang pendidikan sarjana kesehatan masyarakat. Untuk lebih jelasnya dapat dilihat dari hasil wawancara mendalam peneliti dibawah ini:

"Kualifikasi pendidikan verifikator kode dirumah sakit sudah sesuai, kan emang tugas perekam medis mengkode kan.. kalo untuk kualifikasi pendidikan verifikator BPJS sih sebenernya kalo tentang kode penyakit atau tindakan medis itukan bukan tugasnya karena verifikator BPJS tersebut tamatan kesehatan masyarakat jadi belum sesuai, kalo menurut kakak.. gtuu". (informan 1)

"Menurut kakak kualifikasi pendidikan verifikator kode untuk dirumah sakit sudah sesuai, soalnya kakak tamatan D-3 rekam medis, kalo verifikator BPJS kakak nggk tau sesuai atau nggknya tapi dia tamatan sarjana kesehatan masyarakat". (informan 3)

"mm,, Kalau menurut kakak sih sebenernya kualifikasi pendidikan untuk melakukan verifikasi kode bukan tugas kakak tapi karena kakak berpengalaman dan ada diberikan pelatihan yaa jadinya bisalah". (informan 4)

Hasil analisa peneliti tentang kualitatif pendidikan verifikator di RS Umum Citra Bunda Medical Center Padang, untuk verifikator kodenya sudah sesuai dengan berlatar belakang pendidikan D3 rekam medis akan tetapi, latar belakang pendidikan verifikator BPJS belum sesuai, yaitu sarjana kesehatan masyarakat. Seharusnya untuk kode tindakan medis tersebut nantinya yang memverifikasi adalah yang berprofesi sebagai perekam medis yaitu sebagai koder, dimana koder tersebut adalah yang berprofesi sebagai perekam medis, yang sudah dijelaskan pada [10] bahwa perekam medis mempunyai kewenangan dalam melaksanakan pengklasifikasi klinis dan pengkodean suatu penyakit dan pengkodean tindakan medis yang sesuai dengan terminologi medis yang benar.

\section{Pelatihan}

Berdasarkan hasil penelitian yang peneliti lakukan dengan wawancara mendalam tentang pelatihan yang telah diikuti verifikator di RS Umum Citra Bunda Medical Center Padang didapatkan hasil bahwa sudah mengikuti pelatihan sekiar 3 kali untuk verifikator kode dan sudah sering untuk verifikator BPJS. Untuk lebih jelasnya dapat dilihat dari hasil wawancara mendalam peneliti dibawah ini:

"Pelatihan untuk verifikator kode dirumah sakit sih sudah ada.. dan sudah mengikuti pelatihan tersebut sekitar 3 kali lah gtu..” (informan1)

"ada, sekitar 3 kali setelah mengikuti pelatihan kakak jadi lebih nambah ilmunya". (informan 3)

"mm.. Kalau ikut pelatihan kakak sering, ini aja baru kemaren ini pulang pelatihannya". (informan 4)

Pelatihan adalah bagian dari pendidikan yang menyangkut proses belajar untuk memperoleh dan meningkatkan keterampilan di luar sistem pendidikan diaman berlaku diwaktu yang relative singkat dengan metode yang digunakan adalah praktek dari pada teori [11]. 
Berdasarkan penelitian dari [12] yang berjudul "Pencapaian Standar Pengolahan Rekam Medis Sebelum dan Sesudah Pelatihan Di RSUD Pacitan", hasil analisa terhadap pengisian identitas kepada pasien dilihat dari kelengkapan sebelum dan sesudah pelatihan bahwa sebelum pelatihan, petugas hanya mengisi identitas pasien 5 item seperti nomor rekam medis, nama, jenis kelamin, tanggal lahir (umur) dan alamat rumah. Namun setelah pelatihan adanya perbaikan dari petugas rekam medis untuk melengkapi item pengisian pada identitas pasien. Tambahan item diluar 5 item antara lain: nomor telepon, agama, status perkawinan, pekerjaan dan nama ibu. Hasil analisa peneliti untuk pelatihan didapatkan hasil bahwa verifikator kode dan verifikator BPJS sudah mendapatkan pelatihan.

\section{b. Sarana dan Prasarana}

1. Terpenuhinya Sarana Prasarana

Berdasarkan wawancara mendalam kepada informan 3 dan 4 mengenai sarana dan prasarana didapatkan informasi bahwa dalam memverifikasi kode tindakan medis di RS Umum Citra Bunda Medical Center Padang sudah terpenuhi. Untuk lebih jelasnya dapat dilihat dari hasil wawancara mendalam peneliti kepada informan dibawah ini:

"sudah terpenuhi, seperti sarana ee sarananya komputer, ICD-10, ICD-9, resume, hasil penunjang medis, sama.. administrasi ee administrasi lainnya kayak laporan operasi, laporan anastesi”. (informan 3)

"mm, kalo sarana prasarananya sudah terpenuhi.. emm kayak ada seperangkat komputer, resume medis, hasil penunjang medis, mm apaa ada INA-CBG's juga sama ICD-9". (informan 4)

\section{Hambatan dan Kendala}

Pertanyaaan terkait tentang kesulitan atau kendala verifkator pada informan 3 dan 4 . Menurut informan 4 hambatan dan kendala pada verifikasi kode yaitu tulisan dokter yang terdapat di resume medis tersebut sulit dibaca dan adanya perbedaan persepsi. Untuk lebih jelasnya dapat dilihat dari hasil wawancara mendalam peneliti dibawah ini:

"ee kalo kendalanya kita sih biasanya baca tulisan dokter jadinya kita lapor ke bagian case manager untuk konfirmasi tulisan itu ke DPJP, jadinya lama pengkodean tindakan medis untuk klaim itu”. (informan 3)

"mm palingan ya kendalanya itu, karena tulisan dokter yang susah dibaca, trus adanya perbedaan persepsi untuk kode tindakan medis". (informan 4)

Hasil analisa didapatkan yang mendukung kegiatan sarana prasarana dalam pelaksanaan verifikasi kode tindakan medis di RS Umum Citra Bunda Medical Center Padang sudah terpenuhi, tetapi berdasarkan hasil wawancara dan observasi telah dilakukan oleh peneliti dapat dilihat adanya seperangkat komputer, aplikasi INA-CBG's, ICD-9 CM, printer, serta status pasien yang akan dikode tindakan medisnya. Namun, walaupun sarana dan prasarana nya sudah lengkap tetapi masih ada kendala yang terjadi, seperti komputer terkadang error dan tulisan dokter yang sulit dibaca oleh verifikator. Solusinya untuk kendala tersebut yaitu ketika komputer error adalah verifikator memanggil orang IT yang ada di rumah sakit, untuk tulisan dokter yang sulit dibaca verifikator kode adalah melapor kepada bagian case manager dan nanti akan dikonfirmasi oleh case manager kepada DPJP.

\section{c. Standar Operasional Prosedur (SOP)}

1. Ketersediaan SOP

Hasil wawancara mendalam kepada informan 1 dan 3 dalam bentuk kebijakan untuk memverifikasi kode tindakan medis di RS Umum Citra Bunda Medical Padang adalah 
dengan memiliki SOP. Hal ini dilihat hasil wawancara dan observasi yang dilakukan oleh peneliti sebagai berikut:

"SOP yaa.. SOP sudah adaaa, di bagian casemix ada SOP, dan sudah sesuai pelaksanaannya". (informan 1)

"SOP nya ada dan sudah sesuai dengan pelaksanaan verifikasi kode, kan kita memang bekerja sesuai SOP tapi SOP nya tidak ada diruangan casemix soalnya kami baru pindah ruangan". (informan 3 ).

\section{Sosialisasi SOP}

Hasil wawancara mendalam kepada informan 1 dan 3 mengenai Standar Operasional Prosedur diperoleh informasi bahwa sosialisasi SOP untuk memverifikasi kode tindakan medis di RS Umum Citra Bunda Medical Center Padang menurut informan 1 sudah ada dilaksanakannya sosialisasi SOP pada ruangan casemix. Hal ini dilihat hasi dari wawancara mendalam yang dilakukan oleh peneliti didapatkan hasil:

"Kalo sosialisasikan SOP sudah dilakukan diruangan casemix karena verifikator kode kan berada didalam ruangan casemix". (informan 1,3)

Berdasarkan hasil penelitian yang peneliti lakukan dengan cara observasi SOP verifikasi kode tindakan medis tersebut sesuai dengan hasil wawancara mendalam peneliti bahwa tidak adanya SOP tersebut didalam ruangan casemix. Hasil penelitian ini sesuai dengan penelitian [13] dari segi minimalisasi kesalahan, keberadaan SOP dikedua departemen dirasa sudah berfungsi baik untuk mengurangi terjadinya kesalahan yang dapat mengakibatkan pemborosan dan kerugian.

SOP (Standar Operasional Prosedur) berisikan urutan langkah-langkah (urutan pekerjaan), dimana pekerjaan dilakukan, adanya hubungan, bagaimana caranya, dimana dan siapa yang akan melakukannya (Moekijat, 2008). Hasil analisa peneliti ditemukan bahwa SOP untuk verifikasi kode tindakan medis sudah ada dan sudah sesuai, sudah adanya sosialisasi SOP kepada petugas verifikator kode. Akan tetapi peneliti tidak melihat SOP tersebut di ruangan casemix yang semestinya SOP tersebut harus ada di ruangan tersebut atau tertempel di meja kerja verifikator tersebut. Menurut peneliti, seharusnya jika memang ada SOP tersebut, maka lebih baik lagi SOP tersebut di tempelkan didalam ruangan casemix atau dimeja verifikator kode.

\section{Komponen Proses}

a. Pelaksanaan

1. Pelaksanaan Kegiatan

Berdasarkan hasil dari wawancara dan observasi yang dilakukan oleh peneliti dengan informan 3 dan 4 mengenai pelaksanaan verifikasi kode tindakan medis diperoleh informasi dari informan 3 bahwa pelaksanaan verifikasi kodenya berdasarkan pada diagnosa dan tindakan medis yang menghabiskan sumber daya paling banyak sedangkan menurut informan 4 untuk pelaksanaan verifikasi kodenya berdasarkan severity level diagnose atau tindakan medisnya. Untuk lebih jelasnya dapat dilihat dari hasil wawancara mendalam peneliti kepada informan dibawah ini:

"Nah seperti, ini kan disini nih diagnosa utamanya ulkus dm tapi dia ada tindakan $H D$ yang mana sih dia yang yang menghabiskan sumber daya paling banyak $t$ dia yang harus jadi kode utamanya, kayak gtu”. (informan 3)

"ehemm, biasanya sih verifikasinya dilakukan sama pihak rumah sakit lewat aplikasi INA-CBG's dan mengajukan klaim, jadi dicek juga satu-satu semua klaim tersebut sesuai nggk sama diagnose utamanya sama tindakan medisnya, trus ada gk kode tersebut dihasil penunjangnya, lalu eemm. biasanya kita lebih memperhatikan kodenya berdasarkan severity level". (informan 4) 
2. Hambatan dan Kendala

Pertanyaaan terkait tentang kesulitan atau kendala verifkator pada Informan 3 dan 4 . Menurut informan 4 hambatan dan kendala pada verifikasi kode yaitu tulisan dokter yang terdapat di resume medis tersebut sulit dibaca dan adanya perbedaan persepsi. Untuk lebih jelasnya dapat dilihat dari hasil wawancara mendalam peneliti dibawah ini:

"ee kalo kendalanya kita sih biasanya baca tulisan dokter jadinya kita lapor ke bagian case manager untuk konfirmasi tulisan itu ke DPJP, jadinya lama pengkodean tindakan medis untuk klaim perbedaan persepsi untuk kode tindakan medis". (informan 4)

Proses adalah kegiatan atau aktifitas dari seluruh karyawan dan tenaga profesi dalam interaksinya dengan pelanggan eksternal (pasien, pemasok barang, masyarakat yang datang ke puskesmas/rumah sakit untuk keperluan tertentu [14].

Menurut [15] persepsi adalah rangsangan yang diterima oleh susunan syaraf, proses selanjutnya adalah menginterprestasikan stimulus tersebut. Interprestasi adalah penafsiran atau terjemahan, sedangkan sensasi adalah penerimaan dari luar dan masuk kedalam kepala. Proses awal kita akan lalui dalam menafsirkan suatu objek adalah perhatian, jika kita tidak memusatkan perhatian pada suatu objek maka kita tidak dapat menafsirkan atau mengambarkan objek yang telah kita perhatikan.

Hasil analisa peneliti bahwa pelaksanaan verifikasi sudah sesuai dilakukan oleh verifikator kode sedangkan oleh verifikator BPJS belum sesuai karena verifikator kode untuk mengkode tindakan medis utamanya itu berdasarkan yang mana banyak menghabiskan sumber daya paling banyak, sedangkan verifikator BPJS berpikir untuk kode tindakan medis tersebut berdasarkan berdasarkan severity level. Kendala untuk verifikasi kode tindakan medis yaitu tulisan dokter yang sulit dibaca.

Menurut peneliti, seharusnya rumah sakit menyediakan daftar tabulasi untuk diagnose utama, tindakan medis, melakukan monitoring evaluasi kepada dokter, agar ketika menulis tindakan medis tersebut menjadi lebih jelas dan mudah dipahami oleh koder. Untuk perbedaan persepsi tersebut sebaiknya rumah sakit mengadakan seminar untuk kode yang perbedaan persepsinya berbeda tersebut dengan pihak BPJS agar pending klaim karena perbedaan persepsi tersebut dapat teratasi.

\section{b. Monitoring dan Evaluasi}

1. Pelaksanaan Monitoring evaluasi

Berdasarkan dari hasil wawancara dan observasi yang mendalam dengan informan 1 dan 2, diperoleh informasi bahwa menurut informan 2 kegiatan tersebut didapat dengan cara mengecek kelengkapan klaim, lengkap atau tidak formulir yang diisi oleh dokter, lalu lihat kekonsistenannya itu tepat atau tidak kodenya. Untuk lebih jelasnya dapat dilihat dari hasil wawancara dan observasi mendalam oleh peneliti kepada informan dibawah ini:

"Pelaksanaan monitoring evaluasi sudah ada dilakukan, bagaimananya itu yaa sudah dilaksanakanlah dengan baik, hanya saja ee perbedaan persepsi ini belum juga bisa teratasi gtu, ee kalo misalnya terjadi terus-terusan sih sebenernya bisa merugikan rumah sakit yaa gtu." (informan 1)

"Nah, disana t kami mengeceknya t yang pertama kayak kelengkapan klaim, lengkap atau nggk diformulir resume medis yang diisi dokter, trus apa konsisten gk diagnosanya trus apakah kode tindakannya tu tepat atau tidak, apakah petugas sebelum melakukan kode mengecek dahulu hasil penunjang medis sebelum mengkode tindakan medis". (informan 2)

\section{Monitoring dan Evaluasi}

Berdasarkan hasil wawancara dan observasi mendalam peneliti dengan informan 1 dan 2 mengenai yang mengikuti monitoring dan evaluasi untuk lebih jelasnya dapat dilihat dari hasil wawancara mendalam peneliti kepada informan dibawah ini: 
"yang mengikuti monitoring evaluasi itu adalah verifikator kode, kemudian penunjang medis, komite medis, dan direktur rumah sakit yang ikut dan menghadiri rapat monitoring evaluasinya" (informan 1)

"Seharusnya kan yang mengikuti ee monev inikan semua dari petugas yang terlibat dan terkait dalam proses monev itu" (informan 2)

3. Jadwal Monitoring dan Evaluasi

Berdasarkan hasil wawancara yang mendalam peneliti dengan informan 1 dan 2 mengenai jadwal dalam Monev untuk lebih jelasnya dapat dilihat dari hasil wawancara mendalam peneliti kepada informan dibawah ini: "jadwalnya itu setiap 3 bulan 1 kali dalam setahun, seharusnya menurut kakak ya monitoringnya dilakukan sekali sebulan karena jika tidak dilakukan akan terjadi terus perihal persepsi ini gtu..." (informan 1,2)

Monitoring dan evaluasi digunakan untuk memastikan bahwa yang di planning betulbetul dilaksanakan, input sudah ada dan proses telah dilakukan seperti rencana yang sudah ditetapkan, sehingga membuahkan hasil yang lebih baik [14].

Menurut peneliti walaupun kegiatan monitoring evaluasi sudah dijadwalkan sebanyak 3 bulan sekali dalam 1 tahun, namun itu masih kurang maksimal, seharusnya kegiatan monev tersebut dilakukan setiap bulannya agar tingkat pengawasannya terhadap pending klaim itu lebih bagus lagi dan berkurangnya kejadian perbedaan persepsi kode tindakan medis tersebut.
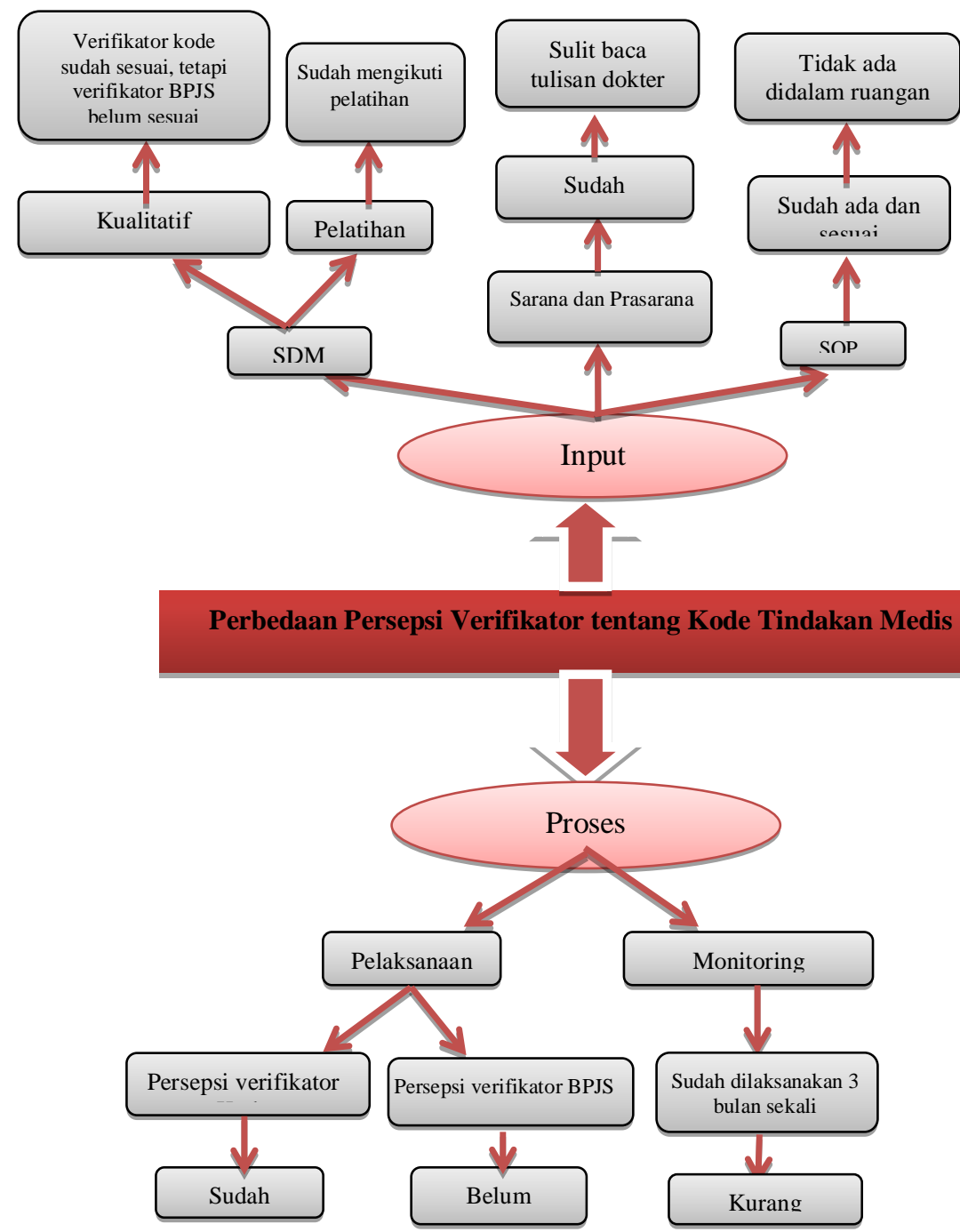

Gambar 1. Peta Konsep Perbedaan Persepsi Verifikator tentang Kode Tindakan Medis 


\section{KESIMPULAN}

Adapun kesimpulan yang dapat diambil dari penelitian ini adalah:

1. Kualifikasi pendidikan verifikator kode sudah sesuai, tetapi untuk verifikator BPJS belum sesuai karena latar belakang pendidikan verifikator BPJS tersebut adalah sarjana kesehatan masyarakat.

2. Untuk pelatihan sudah didapatkan oleh kedua verifikator sudah ada.

3. Untuk pelaksanaan sarana prasarana verifikasi kode tindakan medis sudah mencukupi dengan baik. Masih ada hambatan yaitu komputer yang kadang suka error sehingga verifikator memanggil petugas IT yang ada di rumah sakit. Tulisan DPJP (Dokter Penanggung Jawab Pasien) yang sulit dibaca oleh verifikator, karena terjadi hal seperti itu verifikator melapor kepada case manager lalu nanti case manager yang konfirmasi kepada DPJP.

4. Untuk SOP dalam pelaksanaan verifikasi kode tindakan medis sudah tersedia dan sudah disosialisasikan pada ruangan casemix, namun SOP tersebut tidak ada tertera atau tertempel dalam ruangan casemix.

5. Pelaksanaan verifikasi kode tindakan medis sudah dilaksanakan dengan baik.

6. Perbedaan persepsi untuk kode tindakan medis dikarenakan verifikator BPJS berpikir untuk kode tindakan medis tersebut berdasarkan severity levelnya sedangkan menurut verifikator kode berdasarkan sumber daya yang paling banyak dihabiskan.

7. Kegiatan monitoring evaluasi telah dilakukan dan diikuti oleh verifikator kode, penunjang medis, komite medis, dan direktur rumah sakit. Jadwal pelaksanaan sudah ditetapkan yaitu: 1 kali dalam 3 bulan.

\section{REFERENCES}

[1] D. Mardiawati and D. Leonard, "Analisis Pelaksanaan Pengodean Tindakan Medis Pasien JKN Di RSI Siti Rahmah Padang," Jurnal Endurance: Kajian Ilmiah Problema Kesehatan, vol. 3, no. 3, Art. no. 3, Oct. 2018, doi: 10.22216/jen.v3i3.2764.

[2] L. Indawati, "Analisis Akurasi Koding Pada Pengembalian Klaim BPJS Rawat Inap Di RSUP Fatmawati Tahun 2016," Jurnal Manajemen Informasi Kesehatan Indonesia (JMIKI), vol. 7, no. 2, Art. no. 2, Oct. 2019, doi: 10.33560/jmiki.v7i2.230.

[3] R. DPR, "UU No. 40 Tahun 2004 tentang SJS." http://www.jkn.kemkes.go.id/attachment/unduhan/UU\%20No.\%2040\%20Tahun\%20 2004\%20tentang\%20SJSN.pdf (accessed Jan. 12, 2021).

[4] R. Kemenkes, Permenkes No. 71 Th 2013 ttg Pelayanan Kesehatan Pada JKN. 2013. Accessed: Jan. 11, 2021. [Online]. Available: https://www.kemkes.go.id/resources/download/general/PMK\%20No.\%2071\%20Th $\% 202013 \% 20 \mathrm{ttg} \% 20$ Pelayanan\%20Kesehatan\%20Pada\%20JKN.pdf

[5] R. DPR, "UU_No._44_Th_2009_ttg_Rumah_Sakit." https://dinkes.bantenprov.go.id/upload/article_doc/UU_No._44_Th_2009_ttg_Ruma h_Sakit.pdf (accessed Jan. 12, 2021).

[6] Menteri Kesehatan, "Permenkes No. 147/MENKES/PER/I/2010 Tahun 2010 tentang Perizinan Rumah Sakit." https://peraturan.bpk.go.id/Home/Details/139972/permenkes-no147menkesperi2010-tahun-2010 (accessed Jan. 11, 2021).

[7] Menteri Kesehatan, "Permenkes No. 269/Menkes/Per/III/2008: Rekam Medis." https://ngada.org/menkes269-2008.htm (accessed Jan. 11, 2021).

[8] Menteri Kesehatan, "Permenkes Nomor 28 Tahun 2014 tentang Pedoman Pelaksanaan Program Jaminan Kesehatan Nasional,” 2018. 
https://www.kemhan.go.id/itjen/wp-content/uploads/2017/03/bn874-2014.pdf (accessed Jan. 11, 2021).

[9] R. Kemenkes, Permenkes Nomor. 27 Tahun 2014 tentang Petunjuk Teknis SISTEM INDONESIAN CASE BASE GROUPS (INA-CBGs). 2014. Accessed: Jan. 11, 2021. [Online].

Available: http://www.jkn.kemkes.go.id/attachment/unduhan/PMK\%20No.\%2027\%20ttg\%20Ju knis\%20Sistem\%20INA\%20CBGs.pdf

[10] R. Menteri Kesehatan, PERMENKES nomor 55 tahun 2013 tentang pekerjaan perekam medis. Accessed: Jan. 11, 2021. [Online]. Available: http://pelayanan.jakarta.go.id/download/regulasi/peraturan-menteri-kesehatannomor-55-tahun-2013-tentang-pekerjaan-perekam-medis.pdf

[11] N. Soekidjo, Pendidikan dan Perilaku Kesehatan. Jakarta: PT Rineka Cipta, 2003.

[12] K. E. Werdani, "Pencapaian Standar pengolahan Rekam Medis Sebelum dan sesudah pelatihan Di RSUD Pacitan," vol. 4 No.1, pp. 62-66, 2016.

[13] Gabriele, "Analisis Penerapan Standar Operasional Prosedur (SOP) di Departemen Marketing dan HRD PT Cahaya Indo," vol. 6, no. 1, 2018.

[14] Bustami, Penjaminan Mutu Pelayanan kesehatan danAkseptabilitas. Jakarta: Erlangga, 2011.

[15] N. Soekidjo, Pendidikan dan Perilaku Kesehatan. Jakarta: PT Rineka Cipta, 2003.

\section{BIOGRAPHIES OF AUTHORS}

\begin{tabular}{|l|l|}
\hline & $\begin{array}{l}\text { Dewi Mardiawati, S.SiT., M. Biomed. Tamatan D4 Kebidanan Pendidik Politeknik } \\
\text { Kementrian Kesehatan Padang (Poltekes Padang), dan S2 Biomedik Universitas } \\
\text { Andalas Padang. Saat ini aktif sebagai dosen di Prodi D3 Rekam Medis dan } \\
\text { Informasi Kesehatan STIKes Dharma Landbouw Padang. }\end{array}$ \\
\hline & $\begin{array}{l}\text { Dr. Linda Handayuni, S.KM., M. Kes. Tamatan S1 Kesehatan Masyarakat } \\
\text { Universitas Andalas Padang, dan S2 Ilmu Lingkungan Universitas Negeri Padang } \\
\text { serta S3 Ilmu Lingkungan Univeritas Negeri Padang. Saat Ini aktif sebagai dosen di } \\
\text { Prodi D3 Rekam Medis dan Informasi STIKes Dharma Landbouw Padang. }\end{array}$ \\
\hline
\end{tabular}

